\title{
Música e rádio na China Maoísta (1949-1976)
}

\section{Music and radio in Maoist China (1949-1976)}

\author{
iD Sofia Beatriz Ferreira da Silva \\ Centro de Estudos de Sociologia e Estética Musical \\ Faculdade de Ciências Sociais e Humanas da Universidade Nova de Lisboa, Lisboa, Portugal \\ a2019104567 @campus.fcsh.unl.pt
}

Luzia Aurora Valeiro de Sousa Rocha Centro de Estudos de Sociologia e Estética Musical Faculdade de Ciências Sociais e Humanas da Universidade Nova de Lisboa, Lisboa, Portugal luzia.rocha@fcsh.unl.pt

Resumo: O presente artigo constitui um ponto de partida para um estudo mais aprofundado sobre a relação música-rádio-propaganda na China governada por Mao Zedong. Num exercício de demonstração da rádio como instrumento de veiculação ideológica e de incitamento à participação das massas no trabalho produtivo e na vida política - o que se traduz na prevalência da escuta coletiva em detrimento da individual -, o trabalho sugere o papel da música como complemento ao conteúdo informativo, quer através da composição da programação musical, quer por via da sua inclusão em atividades de audição coletiva.

Palavras-chave: Rádio. Audição coletiva. Programas musicais. Propaganda.

\begin{abstract}
This article is intended to be a starting point for further study on the relationship between music, radio, and propaganda in China under Mao Zedong. As an attempt to present the role of radio as an instrument of ideological dissemination and incitement to the participation of the
\end{abstract}


masses in productive work and political life - reflected in the prevalence of collective listening over individual listening - the paper suggests music as a complement to news content, either through the content of musical programs or through its inclusion in collective listening activities.

Keywords: Radio. Collective Listening. Music Programs. Propaganda.

Submetido em: 23 de março de 2021

Aceito em: 4 de novembro de 2021 


\section{Introdução}

Sendo parte integrante da vida em sociedade, a música exerce influência sobre a forma como os indivíduos agem, pensam e sentem, refletindo as experiências por estes vividas. Assim, esta arte é muito mais do que puro entretenimento: ela é capaz de despertar nos indivíduos a expressão de emoções consoante a situação sociopolítica vivida no momento, permitindo ainda a comunicação de ideias e sentimentos, de valores sociais, morais e ideológicos. Por este motivo, a música pode ser usada por determinado grupo para fins de controlo social, homogeneizando os comportamentos dos indivíduos, validando (ou não) instituições políticas e/ou religiosas, coordenando as ações e movimentos dos indivíduos que integram a sociedade e promovendo a construção de uma identidade cultural e nacional (MERRIAM, 1964, p. 220-222). Assim sendo, a música tem, ao longo dos séculos, vindo a ser usada por determinadas entidades políticas a fim de propagandear e/ou consolidar a sua ideologia e valores junto das populações (SILVA, 2018, p. 73).

Com o desenvolvimento e a popularização da rádio no início do séc. XX, o papel social e político da música ganha novas dimensões, dado que, através desta tecnologia, é possível fazer chegar a música mais longe e a um maior número de pessoas, condição essencial para uma transmissão eficaz da mensagem que se quer fazer passar. As possibilidades da música e da rádio no campo da propaganda foram exploradas ao máximo na Segunda Guerra Mundial, durante a qual os países do Eixo e os Aliados realizavam transmissões de música (oficialmente aprovada) com o intuito de inspirar as populações ou desmoralizar os inimigos. A título de exemplo, durante o cerco a Leninegrado, o governo russo ordenou a transmissão da sétima sinfonia de Shostakovich atrás das linhas inimigas (STEWART, 2017); por outro lado, os Nazis baniram trabalhos do modernismo, impressionismo e expressionismo alemães, dando primazia à transmissão das grandes obras dos grandes mestres, como Beethoven e Wagner (RYBICKI, 2004, p. 95). 
No caso particular da China, desde cedo que os comunistas se aperceberam do papel fundamental que a rádio e a música podiam ter na disseminação dos valores do socialismo e na consequente tomada e consolidação do seu poder (CATHCART, 2004, p. 207). A relação entre ambas as esferas já fora explorada por Hamm (1991), que elaborou um retrato da programação musical da Estação Popular de Transmissão Central (EPTC) e da Rádio Popular de Shanghai e da sua relação com o poder político durante a década de 80 . Porém, o panorama radiofónico musical da China Maoista ainda é relativamente desconhecido no mundo académico, salvo menções esporádicas em estudos ligados à música moderna chinesa. Face a este cenário, torna-se importante a realização de estudos sobre esta temática neste período, por forma a perceber o real impacto da música e da rádio na vida das populações no território chinês e a conhecer melhor o trabalho de propaganda levado a cabo pelo PCC a fim de alcançar os seus propósitos. São estes os principais objetivos deste artigo, o qual, dividido em cinco partes e elaborado com base em literatura cientifica, notícias da época e registos consultados em arquivos provinciais online, se propõe a fazer uma apresentação geral da relação entre estes dois meios de propaganda. Na primeira parte, será feita uma breve passagem pela produção musical chinesa entre 1949 e 1976, período de governação maoísta da República Popular da China (RPC), centrada na composição de canções revolucionárias, as quais dominavam a cena musical da época, servindo como um dos veículos de propagação das ideias e políticas do governo comunista. A segunda parte será dedicada à explanação da estrutura e funcionamento do sistema de rádio chinês do período, essencial para se perceber de que forma eram trabalhados os mecanismos de propaganda através desta tecnologia. De seguida, apresentar-se-á o conteúdo de alguns programas musicais da EPTC e rádios locais e a sua evolução ao longo dos sucessivos movimentos políticos. Na quarta parte, destacam-se quatro canções que, por diferentes razões e devido a diferentes momentos históricos, mascaram as transmissões de rádio da RPC. Por último, far-se-á uma reflexão sobre os grupos de audição coletiva, a quase exclusiva 
forma de escuta de rádio à época, e as suas atividades associadas aos programas musicais radiofónicos.

É de salientar que o trabalho de pesquisa efetuado se encontrou limitado não só pela falta de documentação escrita sobre o tema, como também pela impossibilidade de acesso a arquivos sonoros e outro tipo de documentação histórica, acessível apenas nas próprias estações de rádio, que poderiam enriquecer o trabaIho e comprovar as conclusões dele retiradas. De qualquer modo, o presente artigo pretende, sobretudo, constituir-se como um ponto de partida para uma investigação mais aprofundada, a qual, tendo em conta a importância da música e da rádio para a máquina de propaganda do governo e do Partido Comunista Chinês, vale a pena ser realizada.

\section{A música chinesa entre 1949 e 1976}

O panorama musical chinês de 1949 até ao final da Revolução Cultural foi dominado pela propaganda e imposição de valores de cariz socialista, levada a cabo por Mao Zedong e o Partido Comunista Chinês (PCC). Os preceitos estabelecidos para a arte por Mao determinam que toda a arte, incluindo a música, deveria estar subordinada à política, transmitindo sempre uma mensagem oficial. Esta deveria ainda servir as grandes massas de população (camponeses, operários, soldados e quadros do partido), tendo os artistas de tomar contacto direto com estes grupos, a fim de produzirem obras ricas em conteúdo e corretas no campo ideológico. Face a este cenário, não é de estranhar que a produção musical tenha sido praticamente dominada pelas chamadas 'canções revolucionárias' (geming gequ), compostas por melodias dinâmicas, geralmente do tipo marcha, que apresentavam letras escritas em linguagem vernacular, acessível à generalidade das populações, e cujo conteúdo variava conforme a situação sociopolítica vivida. 
Com a instauração da República Popular da China (RPC) em 1949, o conteúdo da música composta centrou-se sobretudo no apelo à construção da nação e na sátira ao imperialismo no contexto da guerra da Coreia. Para Liang (1993, p. 2), este é considerado o período mais bem-sucedido na criação de canções revolucionárias, fruto das políticas governamentais para a arte e de uma atmosfera artística democrática. Por outro lado, a falta de competência técnica e a pouca diversidade de tipos de canções e temáticas são apontados como os principais problemas do desenvolvimento musical deste período. Uma possível explicação para a existência destes problemas baseia-se na ainda jovem estrutura governativa e nas medidas artísticas adotadas.

Durante o Grande Salto em Frente (dayuejin, 1958-1961)1', a ideia de música ao serviço do povo e da política ganhou ainda mais força, incentivando as massas ao trabalho produtivo e à atuação segundo os ideais comunistas, considerados como os mais adequados ao desenvolvimento do país. A produção musical deste período ficou marcada pelo exagero no elogio ao socialismo e pela dissociação do conteúdo das canções do quotidiano do povo, tendo como principais temáticas as 'três bandeiras vermelhas'², a vida e os feitos do povo chinês e o incentivo e entusiasmo para a produção.

A Revolução Cultural (wenhua dageming, 1966-1976)³ tem como principal acontecimento artístico o estabelecimento por Jiang Qing, mulher de Mao, dos 'Oito Espetáculos-Modelo' (yangbanxi), os únicos permitidos à época, compostos por cinco óperas revolucionárias, dois bailados modernos e uma sinfonia. Na primeira fase deste período (1966-1968), o panorama musical chinês consistia nas canções-citação $0^{4}$ e nas canções compostas pelos Guardas Vermelhos, as quais propagandeavam o culto a Mao Zedong e o apelo à rebelião.

\footnotetext{
1 Programa com vista à aceleração do Programa de Superpotência idealizado por Mao, com o propósito de encurtar o prazo para a aceleração da industrialização do país de dez a quinze anos para cerca de oito anos. Neste sentido, o objetivo final seria ultrapassar todos os países capitalistas num espaço de tempo relativamente curto e tornar-se num dos países mais ricos, avançados e poderosos do mundo (CHANG, citado em SILVA, 2018, p. 49).

2 Eram elas as linhas gerais do partido, o Grande Salto em Frente e as comunas populares.

3 Movimento iniciado por Mao Zedong que pretendia o revivalismo do espírito revolucionário comunista através da total eliminação de todos os elementos evocativos da sociedade capitalista e da cultura tradicional chinesa (considerada 'burguesa' e 'feudal'), que incluía a purga/condenação de todos aqueles cujas ideias se opunham às do líder do PCC.

4 Canções compostas para as citações de Mao presentes no "Livro Vermelho", principal texto a ser estudado durante a Revolução Cultural.
} 
Entre 1968 e 1971, depois das críticas de Jiang Qing à música composta para o Nono Congresso do Partido Comunista Chinês, houve uma total ausência de produção musical, sendo apenas permitido um número muito limitado de canções e os espetáculos-modelo. A partir de 1971 e depois dos vários apelos a uma democratização na arte feitos por Zhou Enlai, assistiu-se a um novo retorno à composição e investigação musical com a compilação das "Novas Canções do Campo de Batalha" (zhandi xinge), uma antologia de cinco volumes constituída por canções escolhidas consoante o conteúdo político e forma artística, representativas de vários estratos da população e das minorias étnicas.

\section{Funcionamento e difusão das transmissões de rádio}

Assim que iniciaram o governo da República Popular da China, os comunistas estabeleceram um sistema de transmissão de rádio centralizado, a partir da reorganização das estações existentes e da criação de novas estações. No topo da hierarquia, encontra-se a Estação Popular de Transmissão Central (zhongyang renmin guangbo diantai, EPTC), fundada em dezembro de 1949, que coordena todas as estações nacionais e a sua programação. Abaixo desta, encontram-se as estações ao nível das províncias, municípios ${ }^{5}$ e regiões autónomas ${ }^{6}$ e, por último, as estações de cada condado, cidade e/ ou aldeia. As rádios pertencentes a estes níveis administrativos, representantes da autoridade governamental daquelas regiões, monitorizavam e retransmitiam a programação das estações centrais e dos níveis superiores, para além de realizarem os seus próprios programas (LIU, 1975, p. 118-119). De entre estas, existem estações direcionadas para as minorias étnicas cuja língua materna não é o mandarim.

\footnotetext{
5 Regiões administrativas de nível provincial controladas diretamente pelo governo. Na era de Mao, eram consideradas municípios as cidades de Pequim, Tianjin e Shanghai, às quais se viria a juntar, em 1997, a cidade de Chongqing.

6 Regiões administrativas de nível provincial nas quais a maior parte da população pertence a uma determinada minoria étnica, tendo, portanto, legislação especial que lhe permite exercer os seus costumes e práticas culturais. No total, existem 5 regiões deste tipo: Mongólia Interior (etnia mongol), Guangxi (etnia Zhuang), Ningxia (etnia Hui), Xinjiang (etnia Uigur) e Tibete (etnia tibetana).
} 
Apesar de conscientes acerca da falta de recursos e de infraestruturas para o estabelecimento e difusão das transmissões via rádio, os comunistas chineses decidiram usar esta tecnologia como um dos seus principais veículos de propaganda, pelo facto de a rádio ser uma tecnologia com uma forte tendência de acessibilidade para as pessoas analfabetas, e devido ao efeito psicológico que exerce sobre o ouvinte (COOPER, 2017, p. 55). Em 1950, numa altura em que as tecnologias de rádio ainda se encontravam pouco desenvolvidas, o governo comunista estabeleceu redes de monitorização de transmissões de rádio, nas quais equipas de monitores apontadas pelas autoridades locais se deslocavam às zonas onde a rádio ainda não estava acessível. Estas equipas tinham como funções:

Ouvir e redigir notícias, instruções políticas e outro conteúdo importante transmitido pelas Estações Populares de Transmissão do centro e das províncias (...), introduzir e anunciar os programas transmitidos pelas estações acima mencionadas e organizar a população local para ouvir programas importantes (como palestas dadas por líderes governamentais e lições especiais sobre ciências sociais (LIU, 1964, p. 4).

No primeiro Plano Quinquenal (1953-1957) ${ }^{7}$, o governo estabeleceu, para os últimos dois anos, o desenvolvimento de estações de transmissão por cabo, as quais iriam substituir as equipas de monitorização. O novo sistema viria a ficar conhecido como rede recetora de transmissão (guangbo shouyin wang) e consistia num sistema de comunicação via rádio ponto a ponto no qual determinados programas de rádio eram selecionados a partir de uma estação recetora, que depois seriam transmitidos através de altifalantes ligados por cabo. Os altifalantes, para além de porem em prática a ideia de audição coletiva do partido, eram, também, mais baratos e fáceis de manter do que o equipamento de transmissão

\footnotetext{
7 Método de planeamento económico gerido ao longo de cinco anos por via do estabelecimento de quotas a cumprir por cada unidade de trabalho. Este primeiro plano foi largamente centrado na criação de uma forte base industrial, suportada por um excedente agrícola.
} 
sem fios, de qualidade superior (COOPER, 2017, p. 56-57). Um operador ligava os altifalantes a um recetor de programas da rádio nacional ou das rádios locais, interrompendo a qualquer momento para fazer anúncios ou transmitir material cultural e educacional concebido especialmente para os seus ouvintes (YU, 1964, p. 124). Em 1960, existiam já 6040000 altifalantes espalhados por todo o território chinês, em comparação com os 3040000 existentes em 1958 e 940000 em 1957 (LEl, 2015, p. 62).

\section{Programação musical}

Os programas artísticos transmitidos na rádio chinesa, nos quais se incluíam os programas musicais, foram e são parte integrante e importante do trabalho de propaganda do partido e variam consoante a função da arte e literatura ao longo das épocas. Em 1955, dá-se a segunda Reunião Nacional do Setor da Rádio, na qual se estabelecem as diretivas e propósitos dos programas musicais: servir os camponeses, operários, soldados e outros quadros do partido, funcionando como meio de educação das massas para o socialismo e o nacionalismo e aumentando a sua cultura musical e nível de apreciação estética (LIU, 1975, p. 115). Os temas centrais da propaganda na EPTC para a produção de conteúdos artísticos eram bastante simples: trabalho árduo, produzir mais, doar mais (de si), amar o Comunismo, detestar os americanos e todos os outros inimigos, confiar no partido e ter fé num futuro brilhante. Os conteúdos propagandísticos ocupavam cerca de $70 \%$ da programação, tendo este número reduzido para cerca de 30\% em 1955, ao passo que os programas de caráter científico e cultural passaram a ocupar mais de metade da programação (YU, 1964, p. 131).

No que concerne à música propriamente dita, os programas da rádio chinesa transmitiam predominantemente canções revolucionárias chinesas e da União Soviética, música regional e das minorias étnicas, óperas regionais e música instrumental nacional e internacional. Ao longo do tempo, foram sendo introduzidas 
algumas palestras de formação musical, incluindo estética, teoria musical, apresentação da música e instrumentos regionais e étnicos e aprtesentação ou análise de canções e óperas, a fim de aumentar o interesse das populações pela música nacional. Era ainda comum a transmissão em direto de concertos de grupos corais e orquestras provenientes de escolas, empresas e unidades industriais, ou grupos formados pelas próprias rádios.

Nos primeiros anos da Estação Central de Transmissão da RPC, entre 1949 e 1953, é transmitida meia hora de conteúdo musical gravado em disco de cera ou fita de metal (LIU, 1975, p. 113). Foi nesta época que começou a ser transmitido o programa "Ensinar a cantar" (jiao changge), no qual um músico ia cantando uma canção em partes e outras pessoas repetiam. As canções a ensinar eram selecionadas tendo em consideração o grau de dificuldade da melodia (quanto mais fácil de cantar esta fosse, mais fácil seria de aprender por parte do ouvinte) e, sobretudo, o momento político vivido no momento da transmissão do programa. De entre estas, constavam a "Marcha dos Voluntários" (yiyongjun jinxingqu), "Todos os Povos do Mundo Unidos num só Coração (quan shijie renmin xin yi tiao) e "Cantando a Pátria" (gechang zuguo).

Entre 1954 e 1963, dá-se o período de maior desenvolvimento na transmissão de programas musicais, fruto do contacto com a União Soviética e, em 1955, é lançado o programa "Canção da Semana" (meizhou yi ge), transmitido uma vez por semana, no qual se apresentava uma canção usando linguagem simples para uma melhor compreensão por parte da população, tendo como objetivos satisfazer as necessidades de apreciação estética do público e incitá-lo a cantar. Como exemplos de canções, destacam-se: "O socialismo é bom" (shehui zhuyi hao), "A minha Pátria" (wo de zuguo) e "Canção das Grandes Ondas" (hongbo qu).

Foram sendo adicionados cada vez mais programas de música de vários tipos, até que, em 1958-59, esta passou a ter lugar de destaque na programação. Entre eles, os programas de música regional e ópera de Pequim eram os mais populares, dado o esforço do governo no ressurgimento e na popularização destes géneros 
musicais. No entanto, é de salientar que poucos destes programas se encontravam isentos de propaganda, dada a capacidade do governo comunista desde o seu surgimento de usar a música regional como ferramenta na propagação dos seus ideais (YU, 1964, p. 135).

Com o Grande Salto em Frente (1958-1961), a transmissão de programas musicais da EPTC passa a servir exclusivamente a política em detrimento da vertente estética e da diversidade musical, fruto do apelo em 1956 para o uso da música como meio de propaganda. Mesmo assim, no mesmo ano, foram lançados os programas "Música Ligeira da China" (zhongguo qingyinyue) e "Festa do Fim do Mês" (yuemo wuhui), para permitir aos ouvintes alguns momentos de descontração. Apesar de uma pequena recuperação em 1962, a maior parte do conteúdo musical transmitido cerca de 90\% - pertencia ao repertório revolucionário, deixando os restantes $10 \%$ para a emissão de música tradicional. A situação, porém, piorou com a Revolução Cultural (1966-1976), durante a qual a transmissão de música na rádio chinesa ficou reduzida a oito canções revolucionárias e oito espetáculos-modelo, devido à crítica e consequente censura por parte de alguns líderes à produção musical do país (LIU, 1975, p. 114).

No caso das emissoras locais, o tipo de programação musical não variava muito da estação central. Tomando como exemplo a Rádio Nacional de Shanghai, os programas musicais baseavam-se no ensino de canções, na sua própria versão da "Canção da Semana", na transmissão de atividades de canto em massa e de grupos musicais pertencentes à própria rádio, ao exército e à classe operária, para além dos programas retransmitidos da EPTC. Todos os domingos de manhã, era transmitido o "Concerto Radiofónico da Semana" (xingqi guangbo yinyuehui), que consistia na apresentação e transmissão de obras da música clássica e moderna ocidental e, como resposta às "exigências dos ouvintes", peças de compositores nacionais como Ma Sicong e Xian Xinghai. Em alturas de celebração de grandes eventos de propaganda, a rádio transmitia também concertos organizados por unidades de trabalho, como o “Concerto Radiofónico do 'Maio Vermelho' do Operariado 
de Shanghai", por ocasião do quinto aniversário da libertação da cidade em 1954; e o "Concerto Radiofónico da Indústria Musical", para celebrar o 37 aniversário do PCC em 1958.

Para aumentar o potencial propagandístico da informação transmitida, a rádio passou a incluir canções nos seus programas noticiosos e conteúdo de propaganda nos próprios programas musicais. A música transmitida consistia essencialmente em canções revolucionárias, música nacional e da União Soviética, para além de alguma música dos países "capitalistas". A partir do Grande Salto em Frente, a música transmitida servia os propósitos de propaganda das 'três bandeiras vermelhas', ao passo que, durante a Revolução Cultural, era apenas permitida a transmissão das canções-citação de Mao e de elogio à revolução, canções com letra baseada na poesia escreita pelo presidente, bem como dos espetáculos-modelo (Gabinete de Registos Territoriais de Shanghai, 2002).

\section{As canções que marcaram as transmissões da EPTC}

Para além dos programas especializados na arte musical, o início e o final das emissões diárias da rádio chinesa (tanto da EPTC como das rádios locais) eram pontuados por quatro canções diferentes, escolhidas de acordo com os momentos políticos vividos. Entre 1949 e 1966, era fundamental promover sentimentos como o nacionalismo, a união entre as diferentes etnias que compunham o território chinês e o espírito de luta necessário para a construção e desenvolvimento da nação socialista. Esta era uma tarefa fundamental de todos os órgãos de propaganda, incluindo a rádio, cuja escolha de canções de abertura e encerramento das emissões deveria ter em conta estes propósitos.

Assim, as emissões diárias da EPTC e da maior parte das rádios iniciavam com o hino nacional - a "Marcha dos Voluntários" (yiyongjun jinxingqu) -, inicialmente composta para o filme "Filhos da 
Tempestade" (fengyun ernü) $)^{8}$ em 1935 por Nie Er. Apesar da curta vida ${ }^{9}$, Nie envolveu-se ativamente na política por via do seu talento musical, compondo cerca de trinta e cinco canções que refletiam a vida do povo comum e ensinando-as posteriormente aos grupos visados nos seus trabalhos, bem como da organização de atividades de canto em massa e da fundação da "união de Amizade SinoSoviética". Um mês após a estreia do filme, a "Marcha" tornou-se bastante popular, sendo cantada por multidões tanto nas áreas rurais como urbanas. A canção, cuja letra foi escrita em linguagem vernacular, expressa a determinação e a coragem do povo chinês em sacrificar-se em prol da libertação da nação contra a agressão dos invasores estrangeiros, refletindo a frustração de um povo sujeito à agressão estrangeira durante vários anos e servindo como forma de libertação da sua raiva e de imploração por uma solução (SILVA, 2018, p. 42).

O fecho das emissões e a abertura de alguns programas de informação e programação dirigida às minorias étnicas ficava a cargo da canção "Cantando a Pátria" (gechang zuguo), composta em 1950 por Wang Xin (1918-2007). Contemporâneo de Xian Xinghai e Lü Ji, Wang foi figura ativa no panorama musical revolucionário, tendo estudado na Academia de Artes Lu Xun em Yan'an e tomando parte em equipas de propaganda e delegações aos soldados chineses no estrangeiro antes e depois da fundação da RPC, compondo canções e musicais representativos desses momentos (LIU \& JIN, 2002, p. 24). Criada por Wang por altura do primeiro aniversário da República Popular da China, a canção, do tipo marcha, com um ritmo vigoroso e escrita como representação da voz de todo o povo chinês, revela-se como um elogio à nova nação socialista, expressando a esperança do povo no desenvolvimento próspero da sua terra natal e a união de todas as pessoas na sua construção (LIANG, 1993, p. 4).

\footnotetext{
8 Realizado em 1935 por Xu Xingzhi e com argumento de Tian Han e Xia Yan, o filme, de cariz patriótico, conta a aventura do jovem poeta Xin Baihua e do seu amigo Liang Zhifu, que abandonam a sua terra natal para escapar à invasão japonesa. Enquanto Liang se junta ao movimento de resistência antijaponesa, Xin vive um romance com uma glamorosa viúva em Qingdao, sem, contudo, deixar de mostrar apreensão pela situação sociopolítica da sua pátria e pelo seu amigo. Após a morte de Liang, Xin decide participar na frente de batalha contra os invasores.

9 Nie morreu aos 23 anos, vítima de afogamento, durante uma visita a um amigo no Japão.
} 
O espoletar da Revolução Cultural em 1966 trouxe consigo o culto a Mao Zedong e o apelo à rebelião contra aqueles considerados 'revisionistas' e 'contrarrevolucionários', conduzindo a atos de violência em larga escala e ao quase-estado de guerra civil. Com a purga do letrista da "Marcha", Tian Han, a EPTC e as restantes rádios passaram a iniciar as transmissões com a canção "O Leste é Vermelho" (dongfang hong), considerada o hino nacional não oficial e a canção-símbolo do culto a Mao (KRAUS, 1989, p. 119). A canção tem origem num tema popular da região de Shaanxi (noroeste da China), cuja letra terá sido adaptada em 1942 por Li Youyuan, um camponês do norte da província, descreve os feitos revolucionários do "Grande Timoneiro" e a preocupação que demonstrava pelo seu povo. Neste mesmo período, "A Internacional" (guoji ge), era a canção que encerrava as emissões de rádio. Composta no séc. XIX em França, a canção apela à união de todo o proletariado, oprimido pelo sistema capitalista, na luta contra os grandes proprietários e pela restituição dos seus direitos e bens. No contexto da Revolução Cultural, esta canção teve como principal função a mobilização das massas para o (re)nascimento da revolução chinesa, assente em ideais voluntaristas e idealistas (CHEN, 2016).

\section{Atividades musicais e participação popular}

Embora a escuta de rádio a nível individual fosse também possível para aqueles que possuíam os seus próprios aparelhos, na China de Mao, a forma mais comum para a escuta de programas de rádio era a chamada 'audição coletiva' (jiti shouting), na qual grupos ou assembleias de pessoas eram organizadas em determinado momento e local para assistirem a programas de rádio específicos, assistidos por monitores que asseguravam a correta transmissão das mensagens provenientes de Pequim e que determinadas mensagens que requeressem maior atenção eram discutidas e compreendidas em grupos de estudo (YU, 1964, p. 125). Para além de permitir o acesso à rádio a populações sem 
meios económicos para adquirir esta tecnologia, as audições coletivas permitiam ao governo conseguir legitimação política, reunir o apoio da população e mobilizá-la para a produção agrícola e industrial, bem como para outros tipos de campanhas e movimentos que iam sendo lançados ao longo do tempo (LEI \& SUN, 2017, p. 5).

Pese a escassez de informação disponibilizada, é possível observar a integração da música neste tipo de eventos, quer através da sua organização para audição de determinados programas musicais, quer da sua inclusão em eventos radiofónicos específicos. Cui $(1954$, p. 38) relata que, quando eram transmitidos programas de ensino de canções, eram organizados grupos nas fábricas, escolas e departamentos para as estudarem e cantarem. No caso particular das escolas, os professores de música viam na programação a canção ensinada no dia ou estudavam enquanto durava o programa, ensinando-a, depois, aos seus alunos ou acompanhando o programa com eles, cantando segundo os padrões de ensino veiculados pelo programa (idem). Em Hubei, no ano de 1951, a Estação Popular de Wuhan organizou 14 grupos para estudo de canções e 74 grupos para outros programas musicais, os quais estudavam as canções transmitidas nos programas e as ensinavam aos restantes membros das suas unidades de trabalho e gravavam, por cada transmissão, 15 mil discos (LI, Z., s. d.).

A organização de grandes grupos de audição coletiva (guangbo dahui) era mais comum aquando da propagação de medidas, leis e movimentos importantes, servindo a música como complemento ao conteúdo transmitido. A título de exemplo, durante o movimento "Resistir à América, Ajudar a Coreia", a Rádio Popular de Shanghai organizou uma audição coletiva com o propósito de incutir nas populações a proteção da pátria contra os invasores. Com duração de 5 horas e 30 minutos, a audição coletiva incluiu representantes dos vários quadrantes da sociedade e, para além dos habituais discursos, contou com a transmissão de canções alusivas ao tema (LI, 2019, p. 27). Em 1960, por altura do Grande Salto em Frente e para celebrar o Dia Internacional da Mulher, várias uniões femininas e sindicatos realizaram, em colaboração com a 
Estação Popular Central de Transmissão, um evento de audição coletiva dedicado a estas duas celebrações, o qual terminou com interpretação por parte de todas as mulheres presentes da canção "As irmãs cantam em voz alta o Grande Salto em Frente" (CHEN, 1960). No mesmo ano, no contexto das intervenções dos EUA em Taiwan no conflito com a RPC, os estudantes da Universidade de Educação Física de Pequim organizaram um grupo de audição coletiva de ataque aos americanos, acompanhado da canção "Os tigres de papel surgem na sua forma original" (zhilaohu xian yuanxing).

A audição coletiva de determinado programa, sobretudo de cariz noticioso, servia também como mote à criação de grupos de discussão sobre o seu conteúdo e podia incluir a entoação de canções (CATHCART, 2010, p. 207). Foi o caso do comunicado a anunciar o estabelecimento da Revolução Cultural a 13 de agosto de 1966, após o qual, segundo o "Diário do Povo" (1966), foram realizados grupos de discussão por parte de unidades das forças armadas e comunas de Shanghai sobre a diretiva anunciada e entoadas canções revolucionárias como "O Esplendor do Presidente Mao" (mao zhuxi de guanghui). O mesmo jornal relata que em Pequim, no distrito de Xicheng, os trabalhadores da unidade hospitalar da comuna de Fengsheng realizaram uma palestra durante a qual, para além da expressão de caloroso apoio à diretiva por parte dos oradores, pôde ouvir-se "Navegar os Mares Depende do Timoneiro" (dahai hangxing kao duoshou).

Para além dos grupos ou assembleias de audição coletiva, sabe-se que as estações de rádio organizavam periodicamente atividades que apelavam à participação das massas, como concursos, atividades de canto em massa, concertos por parte de artistas amadores e pedidos especiais de canções pelos ouvintes. A título de exemplo, a estação oficial de rádio da cidade de Tianjin, em colaboração ou alternância com outras autoridades locais, organizava atividades de canto em massa, interpretando canções por ela própria recomendadas nos seus programas. A mesma estação, durante a década de 50 , convidava ouvintes de vários quadrantes da sociedade para realizarem performances em direto que eram, 
depois, gravadas (WANG, 2017). Em Shanghai, para além do convite a grupos amadores provenientes de escolas ou unidades fabris no seu programa de ensino de canções, a emissora municipal organizou, na véspera do Dia do Trabalhador de 1952, uma sessão dedicada ao estudo das duas canções a serem entoadas nas manifestações realizadas no dia seguinte, "Todos os Povos do Mundo Unidos num só Coração" e "Cantando a Pátria", as quais, segundo o Gabinete de Registos Territoriais de Shanghai (2002), foram estudadas por mais de cem mil pessoas.

\section{Conclusões}

É do consenso geral que, na China de meados do séc. XX, a rádio era muito mais do que mero veículo de informação e entretenimento; era um instrumento de propaganda altamente ideológico, usado para doutrinar as massas para as políticas e ideias do governo de Mao Zedong e instigá-las à participação no trabaIho produtivo (agricultura e indústria) e nos vários movimentos que se foram desenrolando, como o Grande Salto em Frente e a Revolução Cultural. O sistema de receção de rádio estabelecido em todas as regiões administrativas e a prevalência dos grupos de audição coletiva em detrimento da audição individual atestam esta importância da rádio como instrumento de propaganda.

No que concerne à música e aos programas musicais transmitidos, como parte integrante da máquina de propaganda do governo, serviam como complemento aos programas de informação emitidos, muito embora uma pequena percentagem dos mesmos fosse alocada a conteúdo não-político. Este fenómeno é visível na prática da audição coletiva, cujas atividades eram organizadas tendo em vista a audição de determinado programa musical, como o ensino de canções, ou tendo a música como acompanhamento ou complemento do conteúdo transmitido. Tal como apontado por Lei (2015, p. 57), seria importante perceber como é que as massas, para as quais a rádio ainda era uma novidade, ouviam, 
experienciavam e compreendiam a rádio, especialmente no que concerne a programas nos quais a música era parte integrante, que englobasse não apenas a constituição e organização de grupos de audição coletiva (em grande escala ou de tamanho mais reduzido), como também a sua importância para a criação das memórias coletivas e de possíveis sentimentos de nostalgia por parte das populações em relação a estes períodos tão marcantes na história da China do século XX. Por outro lado, um estudo mais aprofundado à composição e estrutura da programação musical, por via do acesso a arquivos in loco, seria relevante para tentar perceber o modo como as canções ou peças transmitidas eram apresentadas e, consequentemente, a sua contribuição para a perceção das massas relativamente à musica disseminada.

\section{Referências}

CATHCART, Adam. Japanese Devils and American Wolves: Chinese Communist Songs from the War of Liberation and the Korean War.

Popular Music and Society, v. 23, n. 2, p. 203-218, 2010.

CHEN, Juanmei. União Nacional da Mulher realiza, juntamente com outras federações, assembleia de audição coletiva (quanguo funülian deng lianhe juxing guangbo dahui). Disponível em https:// cn.govopendata.com/renminribao/1960/3/6/1/\#240636. Acesso em: 24 de nov. 2019.

CHEN, Xiaomei. Singing "The Internationale": From the "Red Silk Road" to the Red Classics. In: ROJAS, Carlos, \& BACHNER, Andrea (Eds.).

The Oxford Handbook of Modern Chinese Literatures, 2016.

Disponível em https://www.oxfordhandbooks.com/view/10.1093/ oxfordhb/9780199383313.001.0001/oxfordhb-9780199383313-e-10. Acesso em: 20 mar. 2021.

COOPER, Simon. Transmiting Power: Radio and Organization in Maoist China. Senior Projects Spring 2017, n. 122, 2017.

CUI, Guixu. Algumas considerações sobre o ensino de canções via rádio (dui guangbo diantai jiaoge de jidian yijian). Renmin Yinyue, 38, 1954. 
DIÁRIO DO POVO (RENMIN RIBAO). Notícias da segunda versão do “Diário do Povo" de 15 de agosto de 1966 (1966 nian ba yue shiwu ri renmin ribao - di er ban). Disponível em https://cn.govopendata.com/ renminribao/1966/8/15/2/. Acesso em: 18 mar. 2021.

GABINETE DE REGISTOS TERRITORIAIS DE SHANGHAI. Secção 5: Programas Musicais (diwujie: wenyi jiemu). Gabinete de Registos Territoriais de Shanghai, 2002. Disponível em http://www.shtong.gov.cn/ dfz_web/DFZ/Info?idnode=63811\&tableName=userobject 1 a\&id=12206. Acesso em: 27 fev. 2021.

HAMM, Charles. Music and radio in the People's Republic of China. Asian Music, v. 22, n. 2, p. 1-42, 1991.

KRAUS, Richard Curt. Pianos and Politics in China: Middle-Class Ambitions and the Struggle over Western Music. Nova lorque: Oxford University Press, 1989, 288p.

LEI, Wei. Radio and Social Transformation in China. Tese de doutoramento. Faculty of Arts and Social Sciences, University of Technology, 2015. Sydney: Routledge, 2019. 238p.

LEI, Wei, \& SUN, Wanning. Radio Listening and the Changing Formations of the Public in China. Communications and the Public, v. 2, n. 4, p. 320-334, 2017.

\section{$\mathrm{LI}$, Xiaotong. Research on the Propaganda by Broadcasting in the} Early Days of the Movement to Resist U.S. Aggression and Aid Korea: A Case Study of Shanghai People's Radio Station. Tese de mestrado não publicada. East China Normal University, 2019. Shanghai.

LI, Zhi. Programas de rádio (guangbo jiemu). In: LI, Zhi (Ed.). Registos da Cidade de Wuhan - Informação (wuhan digangzhi - xinwenzhi). Disponível em http://szfzg.wuhan.gov.cn/book/dfz/bookread/id/240/ category_id/48516.html. Acesso em: 01 de mar. 2021.

LIANG, Maochun.. Música Moderna da China, 1949-1989 (zhongguo dangdai yinyue 1949-1989). Pequim: Editora da Universidade de Radiodifusão, 1993. p. 257.

\section{LIU, Adrian P.. Radio Broadcasting in Communist China.}

Massachusetts Institute of Technology, Center for International Studies, Massachusetts, 1964. 


\section{LIU, Alan P.. Communication and National Integration in}

Communist China. Londres: The University of California Press, 1975. p. 243.

MERRIAM, Alan P. The Anthropology of Music. Evanston: Northwestern University Press, 1964. p. 338.

RYBICKI, Frank. The Rhetorical Dimensions of Radio Propaganda in Nazi Germany, 1933-1945. Tese de doutoramento não publicada. Duquesne University, 2004.

[Referência ocultada]

STEWART, James. Timeline: World War II, Musical Propaganda. Disponível em https://www.vpr.org/post/timeline-world-war-ii-musicalpropaganda\#stream/0. Acesso em: 18 mar. 2021.

WANG, Ji. Memórias dos programas artísticos dos anos 50 em Tianjin (tianjin wushi niandai wenyi guangbo zayi). Disponível em https://m.sohu.com/a/155333669_231014/?pvid=000115_3w_a. Acesso em: 25 nov. 2019.

YU, Frederick T.C.. Mass Persuasion in Communist China. EUA: Frederick A. Praeger Publisher, 1964. p. 186.

\section{Nota}

A romanização dos carateres chineses incluídos no presente trabalho segue o sistema pinyin, oficialmente adotado na República Popular da China.

\section{Publisher}

Universidade Federal de Goiás. Escola de Música e Artes Cênicas. Programa de Pós-graduação em Música. Publicação no Portal de Periódicos UFG.

As ideias expressadas neste artigo são de responsabilidade de seus autores, não representando, necessariamente, a opinião dos editores ou da universidade. 